\title{
Breeding the dairy cow of the future - what do we need?
}

4

5

6

Donagh P. Berry

7

8

9

Animal \& Bioscience Research Department, Animal \& Grassland Research and Innovation Centre,Teagasc, Moorepark, Fermoy,Co. Cork,Ireland.

Emaildonagh.berry@teagasc.ie

12

13

14

15

16

17

18

19

20

21

22

23 


\section{Abstract}

25

26

27

28

29

Genetics is responsible for approximately half the observed changes in animal performance in wellstructured breeding programs. Key characteristics of the dairy cow of the future include 1) produce a large quantity of high value output (i.e., milk and meat), 2) good reproductive performance, 3) good health status, 4) good longevity, 5) does not eat a large quantity of food, 6) easy to manage (i.e., easy calving, docile), 7) good conformation (over and above reflective of health, reproductive performance and longevity), 8) low environmental footprint, and 9) resilient to external perturbations. Pertinent and balanced breeding goals must be developed and implemented to achieve this type of animal; excluding any characteristic from the breeding goal could be detrimental for genetic gain in this characteristic. Attributes currently not explicitly considered in most dairy cow breeding objectives include product quality, feed intake and efficiency, and environmental footprint; animal health is poorly represented in most breeding objectives. Lessons from the past deterioration in reproductive performance in the global Holstein population remind us of the consequences of ignoring or failing to monitor certain animal characteristics. More importantly, however, current knowledge clearly demonstrates that once unfavourable trends have been identified and the appropriate breeding strategy implemented, the reversal of genetic trends is achievable, even for low heritability traits like reproductive performance. Genetic variation exists in all the characteristics described. In the genomics era, the relevance of heritability statistics for most traits is subdued; the exception is traits not amenable to routine measurement in large populations. Phenotyping strategies (e.g., more detailed phenotypes, larger population) will remain a key component of an animal breeding strategy to achieve the cow of the future as well as providing the necessary tools and information to monitor performance. The inclusion of genomic information in genetic evaluations is, and will continue, to improve the accuracy of genetic evaluations which in turn will augment genetic gain; genomics, however, can also contribute to gains in performance over and above support of increased genetic gain. Nonetheless, the faster genetic gain and thus reduced ability to purge out unfavourable alleles necessitates the appropriate breeding goal and breeding scheme and very close monitoring of performance, in particular for traits not included in the breeding goals. Developments in other disciplines (e.g., reproductive technologies) coupled with commercial struggle for increased market share of the breeding industry, imply a possible change in the landscape of dairy cow breeding in the future.

Keywords: Genetics, heritability, genomic, breeding objective 


\section{Introduction}

Genetics is responsible for approximately half the observed changes in animal performance in well-structured breeding programs; change here implies improvements (e.g., milk production) and deterioration (e.g., reproductive performance). Almost all, if not all, individual characteristics, have a genetic basis. Once genetic variation exists, then breeding for improvement is possible. Moreover, despite antagonistic genetic correlations existing among some traits (e.g., milk production and reproductive performance; Berry et al., 2014b), once the genetic correlations are less than unity, then genetic improvement in all traits is achievable; whether or not this is an appropriate strategy will be determined by the relative (economic) importance of the respective traits.

Lessons from the past suggest that the definition of a holistic and pertinent breeding goal is of fundamental importance. Genomic selection (Meuwissen et al., 2001) is receiving considerable attention of late as a tool to increase genetic gain. If however the most pertinent breeding objective and associated breeding program is not in place, then genomic selection could actually have serious repercussions for gains in dairy herd profit. Not all traits included in a breeding objective are amenable to routine measurement on very large populations from which to estimate breeding values. Controlled experiments on animals divergent for the breeding goal can be efficiently used to elucidate the expected correlated responses to selection for difficult/expensive to measure traits. Thus, the first and most important step in deciding "what do we need" for a successful breeding program is to define the characteristics of the cow of the future. Once defined, the extent of genetic variation governing these characteristics and the genetic inter-relationships among these characteristics can be quantified. The final step is to define the best strategy (i.e., phenotyping, genetic evaluations, exploitation of genomic information) to achieve the desired gains. Continuous evaluation of the performance of the breeding strategies, including genetic change in the different traits and the cost:benefit of alternative breeding strategies, should be routinely undertaken.

\section{Characteristics of the ideal cow}

When initially defining the ideal cow, it is crucial not to 1) overlook traits despite the sometimes perceived lack of genetic variation in the trait, and 2) ignore a trait if it cannot be (easily) measured given the current state-of-the-art. Also, when the objective is to define the ideal cow to guide a breeding program, the ideal cow should be that of the future. Therefore, traits of likely future importance and their associated (societal) values (e.g., environmental footprint) as well as the future production system the cows are likely to be producing in, must be considered. 
1) Produce a large quantity of high value output (i.e., milk and meat)

2) Good reproductive performance

3) Good health status

4) Good longevity

5) Does not eat a large quantity of food

6) Easy to manage (i.e., easy calving, docile)

7) Good conformation (over and above reflective of health, reproductive performance and longevity)

8) Low environmental footprint

9) Resilient to external perturbations

All the aforementioned characteristics cannot be taken in isolation. A cow, for example, that produces a large quantity of high value output but does not eat a large quantity of food will likely enter negative energy balance which in turn has unfavourable ramifications for animal health and reproductive performance (Beam and Butler, 1999; Collard et al., 2000).

Production of a large quantity of high value output. Almost all international dairy cow breeding goals include milk, fat and protein yield. Milk fat is composed of both saturated and unsaturated fats, as well as the respective individual fatty acid components. The correlation, for example, between total milk fat composition and saturated milk fat composition is 0.90 (Soyeurt et al., 2007) suggesting some (limited) variability in the saturated content of fat exists. Similarly, milk protein is composed of a casein and whey fraction as well as the individual protein fractions. Milk processing characteristics (e.g., milk coagulation properties) are also important determinants of milk quality, especially in production systems supplying markets of high value added (speciality) cheeses (Sturaro et al., 2013). Although these individual components currently do not have an explicit economic value in most production systems, they can influence consumer perception of milk products and thus market demand. For example, the average milk fat of a dairy cow contains $70 \%$ saturated fatty acids, $25 \%$ monounsaturated fatty acids and 5\% polyunsaturated fatty acids (Grummer, 1991). Currently dairy products provide $15 \%$ to $25 \%$ of the fat consumption in the average human diet but represents 25 to $35 \%$ of the saturated fat intake (Chillard et al., 2001). Interest has also intensified recently in selection schemes for increased milk lactose yield. The genetic correlation between milk yield and lactose yield is 0.979 (Miglior et al., 2007) indicating limited (but exploitable) genetic gain is achievable.

Although the main source of revenue from dairy herds is milk, beef, through the sale of cull cows and surplus calves, represents $10-20 \%$ of the gross income in most production systems (van der Werf et al. 1998). Thus, beef merit, however defined, is an important characteristic of dairy production and the future dairy cow. The importance of beef characteristics of dairy cows may be 
greater with the availability of low-cost and effective sexed semen as well as production systems where herd size is limited (e.g., finite land in grazing dairy production systems).

Good reproductive performance. The importance of excellent reproductive performance in dairy production systems has been extensively discussed for both seasonal-calving (Shalloo et al., 2014) and confinement (Cabrera, 2014) production systems. Parturition is required for lactation and good reproductive performance is necessary to maximise revenue (e.g., longer lactations in seasonal calving herds) and reduce costs (e.g., hormonal interventions). The importance of superior reproductive performance is greatest in seasonal calving herds where the calving season is synchronised with the availability of low-cost feed (e.g., grazed grass). In seasonal calving herds, compromised reproduction is synonymous with the necessity for involuntary culling. The observed decline in reproductive performance in Holstein dairy cows in most populations until the early 2000's (Berry et al., 2014b) eroded the revenue generated from the concurrent increase in milk production over the same time period (Evans et al., 2006).

Good health status. Not only does sub-optimal animal health erode herd profit through increased medicinal requirements and reduced performance (i.e., yield and reproductive performance) but compromised animal health status also influences consumer perception of modern-day dairy production systems. Some health issues also incur explicit financial penalties; milk price, for example, in most countries is tiered based on the somatic cell count of the herd bulk milk pool. Producers are predominantly concerned with clinical signs of infection but non-observed, often sub-clinical disease, also impairs performance (Dohoo and Martin, 1984; de Graaf and Dwinger, 1996). Past experience from the observed decline in reproductive performance in the global Holstein population (Royal et al., 2000; Evans et al., 2006, Berry et al., 2014b) clearly indicates that monitoring of temporal trends in a trait or suite of traits is vital to identify unfavourable trends early.

Good longevity. A second lactation cow yields approximately 16 to $19 \%$ more than a first lactation cow while a third lactation cow (e.g., mature cow) yields approximately 28 to $31 \%$ more than a first lactation cow (Horan et al., 2005; Walsh et al., 2007). Therefore, achieving good longevity will not only reduce herd replacement cost but will increase herd revenue through the achievement of mature herd yield but also greater calf price of surplus calves from older cows (McHugh et al., 2010). Moreover, younger parity cows are more prone to calving difficulty (Berry et al., 2007; Mee et al., 2011), stillborn calves (Berry et al., 2007; Mee et al., 2008), and disease (Berry and Meaney, 2005) thereby impacting both labour requirements and overall herd profit; of course very old cows are also more prone to some diseases (Roche and Berry, 2006). The impact of reduced replacement rate on herd genetic gain must also be acknowledged; assuming a rate of genetic gain in calves born of $1 \%$ per annum, a halving of replacement rate from $20 \%$ to $10 \%$ (assuming culling is independent of 
genetic merit) equates to a loss in gain of just $0.1 \%$ per annum. In addition to the considerable impact on farm profit, poor cow longevity is also a growing consumer concern.

Does not eat a large quantity of feed. Feed costs represent $50 \%$ to $80 \%$ of the overall costs of production in contrasting dairy production systems (USDA-NASS, 2011; Shalloo et al., 2004). Reducing feed intake, therefore, without any repercussion on the other animal characteristics described is likely to reduce costs and thus improve herd profitability. There is increasing commentary on the use of residual feed intake (RFI) as a measure of efficiency in dairy production systems (Berry and Crowley, 2013) to reduce feed intake without necessarily impacting other performance traits. Selection for (lower) RFI or reduced feed intake is sensible within an overall breeding goal that includes all the aforementioned characteristics. If all the components of statistical model used to derive RFI are included in the breeding objective, then inclusion of either RFI or feed intake in the breeding objective is mathematically equivalent. Although a large proportion $(0.86$; Coleman et al., 2010) of the feed intake phenotypic variation in lactating dairy cows can be explained by the energy sinks and other confounding effects (e.g., year), phenotypic variation in RFI nonetheless exists. Lower feed intake implies lower herd feed costs, but also potentially greater cow numbers in dairy cow grazing production systems.

Easy to manage. Expanding herd size, and in some regions, access to only labour with less expertise in animal husbandry requires an easy-care cow. Characteristics of an easy-case cow not already accounted for (i.e., good health and fertility) include good animal temperament and no requirement for assistance at calving. Polledness is also a management trait, as is the ability of the animal as a new-born calf to be vigorous and ingest and absorb sufficient colostrum. Milking speed could also be considered as an ease of management trait as it affects milking parlour throughput. Berry et al. (2013) reported considerable phenotypic variation in milking duration among animals even after accounting for differences in the associated milk yield (and somatic cell count); the phenotypic correlation between milk yield and milking duration was 0.48. Berry et al. (2013) reported a phenotypic standard deviation of 102.2 seconds per milking for milking duration independent of milk yield; across a 305-day lactation, milked twice daily, this equates to a standard deviation of over 17 hours. Therefore, considerable gains in milking parlour throughput may be achievable with selection for faster milking speed independent of milk yield and udder health.

Good conformation. Certain animal morphological characteristics are phenotypically associated with improved reproductive performance, health (e.g., mastitis, lameness) and longevity (Berry et al., 2005; Larroque and Ducrocq, 2001). Good udder conformation, however, is required for efficient automatic milking and the appropriate animal size is necessary for the design of the milking parlour as well as the housing facilities. Good cow conformation may become more influential on cow longevity as the actual longevity of dairy cows improve through genetic selection. Therefore, 
correlations between cow conformation and longevity may become stronger as factors other than reproductive performance influence the likelihood of culling.

Low environmental footprint. Animal agriculture generates greenhouse gas emissions (GHG) as methane $\left(\mathrm{CH}_{4}\right)$ from enteric fermentation and manure, nitrous oxide $\left(\mathrm{N}_{2} \mathrm{O}\right)$ from the widespread use of nitrogenous fertilizers and animal manure, nitrates from animal excretion, and carbon dioxide $\left(\mathrm{CO}_{2}\right)$ from the fossil fuels for energy usage plus land use change. Methane, however, is not only an environmental hazard but is also associated with a loss of carbon from the rumen and therefore an unproductive use of energy (Johnson and Johnson, 1995). O'Mara (2011) stated that animal agriculture is responsible for 8.0 to $10.8 \%$ of global greenhouse gas emissions based on calculations from the Intergovernmental Panel on Climate Change (IPCC). If however complete lifecycle analysis (i.e., accounting for the production of inputs to animal agriculture as well as change in land use such as deforestation) is undertaken this figure can be up to $18 \%$. Cattle are the largest contributors to global greenhouse gas emissions (O’Mara, 2011).

One element of environmental footprint, practically ignored to date in animal production systems, is the efficiency of water usage. Water is overtaking oil as the world's scarcest critical natural resource (Solomon, 2010). Although the statistic of a 70\% increase in food demand between the years 2010 and 2050 is often quoted (FAO, 2009), less often quoted is the prediction by the United Nations (UNEP, 2008) of a 50\% increase in global water demand between the years 1995 and 2025. Irrigation currently covers $20 \%$ of all cultivated land and is responsible for approximately $40 \%$ of agricultural production (Molden, 2007). Rosegrant et al. (2002) projected that by 2025, 64\% of the world's population will live in water stressed basins, an increase from $38 \%$ in 2006 . Agriculture is by far the greatest user of freshwater in the world (Jury and Vaux, 2007; Morison et al., 2008; Passioura and Angus, 2010) accounting for $70 \%$ of total freshwater use (Steinfield et al., 2006). Therefore low water requirement as well as low methane emissions may be a desirable characteristic of the cow of the future.

Resilient to perturbations. There is considerable commentary on the impact of ruminant production systems on climate change. Less discussed, however, is the impact of climate change on ruminant production systems. Climate change is expected to result in rising global temperature, changes in patterns of precipitation, and more extreme weather events. As well as imposing heat stress on individual animals, such climatic changes may alter the geographical risk areas for certain diseases (Yatoo et al., 2012) which may have implications for animal populations naïve to such diseases. The animal of the future, therefore, as well as achieving all the aforementioned characteristics, will have to be robust to various external perturbations. Because of the definition of heritability, such perturbations are likely to have less impact on higher heritability traits estimated from field data. 
232

233

234

235

236

237

238

239

240

241

242

243

245

246

247

248

249

250

251

252

253

254

255

256

257

258

259

260

Most discussions on breeding programs and genetic gain focus on heritability estimates for different traits. Heritability however is only one of the factors that influences genetic gain. Annual genetic gain for a given trait may be described as (Rendel and Robertson, 1950):

$$
\Delta \mathrm{G}=\frac{\mathrm{i} \cdot \mathrm{r} \cdot \sigma_{\mathrm{g}}}{\mathrm{L}}
$$

where $\Delta \mathrm{G}$ is annual genetic gain; $\mathrm{i}$ is the intensity of selection; $r$ is the accuracy with which you know the genetic merit of each animal, $\sigma$ is the genetic standard deviation, and $\mathrm{L}$ is the generation interval. The accuracy of selection is affected by both the heritability of the trait and the information available on the animal itself and its relatives. Heritability summarises the proportion of phenotypic variation, or differences among a cohort of animals, attributable to genetic variation between individuals. Animal breeders are generally concerned with the narrow sense heritability $\left(h^{2}\right)$, which is the proportion of phenotypic variation attributed to additive genetic variation (i.e., allelic effects transmitted from one generation to the next). Heritability varies from 0 (not heritable) to 1 (fully heritable); heritability estimates for a range of performance traits in dairy cattle are given in Figure 1. In general, traits associated with viability and fitness (i.e., health and reproductive performance) are lowly heritable while traits associated with animal morphological characteristics are more highly heritable corroborating similar observations in other species (Visscher et al., 2008; Falconer and Mackay, 1996).

Figure 2 illustrates the interaction between the number of half-sib progeny records and heritability on the accuracy of selection (ignoring parental contribution). For a given number of progeny, the accuracy will be greater for higher heritability traits. Accuracy of selection of near unity is nonetheless achievable, even for low heritability traits, if sufficient information is available. Therefore, with the appropriate breeding programme (e.g., large paternal half-sib groups, exploitation of genomic information) and infrastructure for the collection and storage of data, genetic gain in low heritability traits is certainly achievable if ample genetic variation is present. Hence, one could argue that the importance of heritability in the genomics era is less compared to historically when evaluating the potential of animal breeding to achieve the cow of the future at a population level. What is important is the extent of genetic variation present. Therefore scientific studies must always report the genetic variance for the traits being evaluated; this information has not always been provided in studies heretofore.

Figure 1 summarises the coefficient of genetic variation for a range of performance traits in dairy cattle. The coefficient of (genetic) variation is used because it is unit-less and therefore facilitates the direct comparison of the variation present in traits differing in mean values but moreso the units of measurement. Although heritability estimates varies considerably across traits, the 
coefficient of genetic variation is relatively consistent across traits $(\sim 5 \%)$. The existence of considerable genetic variation in all traits clearly signifies that once high accuracy of selection is achievable, rapid genetic gain in each of these traits is indeed possible. The actual rate of genetic gain achievable for a trait is a function of the relative (economic) weighting on the trait within the overall breeding goal but also the genetic correlations between that trait and the other traits in the breeding goal.

\section{Derivation of a breeding goal to achieve the ideal cow}

Once the desired animal characteristics to be considered in the breeding goal have been decided, and the existence of genetic variation in these traits demonstrated, the relative importance of each should be quantified. From a breeding perspective, avoidance of double counting should be ensured. For example, in a breeding goal that includes milk production and fertility with their associated relative economic weights, the economic value on health should not include the effect of compromised health on either production or fertility. This is because an animal genetically predisposed to compromised health will also, on average, have inferior genetic merit for milk production and fertility (because of the genetic correlations; Berry et al., 2011a). The economic repercussions of this association will be captured through the economic values and estimated breeding values of the animal for milk production and fertility. This is why the economic values on some traits in breeding goals may appear less than expected.

Some traits currently have no explicit economic value (e.g., greenhouse gas emissions) or the expected responses to selection may not be socially acceptable. For example, the economic values in the UK national dairy cow breeding goal are such that genetic merit for calving interval is expected to deteriorate. This is because it is not economically appropriate to suffer a loss in genetic gain in other performance traits if a greater emphasis is placed on reproductive performance (Berry et al., 2014b). Several studies have proposed approaches on how to best include such traits in breeding objectives (Nielsen et al., 2005; Wall et al., 2010). Desired gains selection indexes or restriction selection indexes (i.e., a form of desired gains index) can be applied to achieve a theoretical gain in these traits. It must be acknowledged that using such desired gains approaches will reduce the expected gain in profit (Gibson and Kennedy, 1990) unless the index weighting on the constrained trait in the unrestricted selection index is zero. Alternative approaches to deriving the relative weights on traits within a breeding goal include interpretation of results from a Delphi study (or other form of survey) or PAPRIKA (Potentially All Pairwise RanKings of all possible Alternatives; Hansen and Ombler, 2009). Whatever the approach, the expected responses to selection should be calculated and ideally these expected responses should be acceptable to stakeholders (e.g., producers, consumers). 

breeding goal due to a perceived dilution in emphasis on the "more important traits". Figure 3 illustrates the expected responses to selection for a given trait based on alternative two-trait breeding goals relative to a breeding goal with only one trait. An accuracy of selection of 0.99 is assumed for both traits and the genetic correlation between the traits is altered from -0.5 to +0.5 . The genetic variance times the relative economic value of the second trait was either equal or double that of the first trait depending on the scenario investigated. It is sometimes (incorrectly) thought that including a trait in a breeding goal with a zero genetic correlation will not impact genetic gain in the other trait(s). For example, such a conclusion is often used when discussing RFI since, if derived using genetic regression, RFI will be independent of the traits included in the regression (i.e., milk production). Figure 3 illustrates that this is not true since it alters the selection intensity for the other traits in the breeding goal. This is more clearly demonstrated in Figure 4 where the top $10 \%$ of animals on a combined index includes, some, but not all of the top $10 \%$ of animals in each trait thereby reducing the selection intensity for each trait and thus genetic gain. Therefore, including RFI derived using genetic regression in a breeding goal will reduce the rate of genetic gain in, for example, milk production; the extent to which it reduces the genetic gain will be a function of the difference in genetic variance and relative weighting on both traits.

The impact of genetic gain in a given trait is expected to reduce as the number of additional traits included in the breeding objective increase. The extent of the reduction in genetic gain for the original trait is dependent on 1) the genetic covariances among the breeding goal traits (reduction is expected to be larger if negative associations exist and the economic weights are the same sign), 2) the weighting on the additional traits relative to the original trait (genetic gain in the original trait is reduced as the relative weight on the additional traits increase), 3) the genetic variance of the additional traits (genetic gain in the original trait is reduced if the relative genetic variance of the additional traits is greater) and, 4) the accuracy of the genetic evaluations of the additional traits based on information on the additional traits themselves (genetic gain in the original trait will be reduced if the accuracy of the genetic evaluations of the additional traits based on information on those traits themselves increase). This phenomenon is illustrated in Figure 5 which depicts the relative genetic gain expected for a given trait as the number of traits included in the breeding goal increases. In this example the genetic variance and economic values of all traits were assumed equal, zero covariances were assumed to exist among all traits, and the accuracy of selection for all traits was 0.99 . Relative to a breeding goal with just a single trait, the genetic gain in the original trait is expected to be $22 \%$ of the original gain when an additional 19 traits are included in the breeding goal. If the relative weighting of all 19 additional traits was just $10 \%$ of the original trait, then the expected genetic gain in the original trait was $91 \%$ of the genetic gain expected with a single-trait breeding goal. 

a breeding goal will adversely affect genetic gain. A two trait breeding goal including protein yield and RFI is assumed with a genetic standard deviation times the relative economic weight on both traits being approximately similar (Bell et al., 2013; Gonzalez-Recio et al., 2014); zero genetic correlation is assumed between both traits. If the reliability of genetic evaluation for RFI is $10 \%$, the genetic gain for protein yield is $96 \%$ that of a breeding goal that included only protein yield (although RFI is expected to also improve); a reliability of $20 \%$ for RFI reduces the genetic gain in protein yield to $91 \%$ of that achievable with single trait selection for protein yield. Based on the scenarios simulated here, although including additional traits in a breeding goal is likely to reduce genetic gain, the impact is expected to be less for the more important traits (assuming the genetic variance of all traits is the same and zero covariances exist). More importantly, inclusion of the additional (important) traits in the breeding goal will increase the overall response to selection on the entire breeding goal (Figure 5).

The relative emphasis on an individual trait $i$ in a breeding goal is usually depicted as the product of the genetic standard deviation times the economic weight of that trait divided by the sum of the same calculation for all traits in the breeding goal:

$$
\text { Emphasis }_{i}=\frac{\left|a_{i} \cdot \sigma_{i}\right|}{\sum_{j=1}^{n}\left|a_{j} \cdot \sigma_{j}\right|} \text {. }
$$

351

where $a_{i}$ and $a_{j}$ is the economic value for trait $i$ and $j$, respectively and $\sigma_{i}$ and $\sigma_{j}$ is the genetic standard deviation for trait $i$ and $j$, respectively. Figure 5 clearly shows how misleading such a calculation can be using the parameters (i.e., same economic weights, same variances, same accuracy of selection and same covariances) already described for a breeding goal with up to 20 traits. The relative emphasis for individual traits in a breeding goal should be expressed based on expected response to selection which can be derived using selection index theory. Another example can be used to emphasise the point. Assume a two-trait breeding goal that includes protein yield and reproductive performance with a genetic correlation of -0.50 (Berry et al., 2014b) between them and each with an accuracy of selection of 0.99 . The same genetic variance is assumed to exist for both traits but the economic weight on protein yield is twice that for reproductive performance. No genetic gain in reproductive performance is expected with such a breeding goal but the relative emphasis on reproductive performance calculated using the approach just described is $33 \%$.

It should also be recognised that because of the linearity of breeding goals, there is a plane along with the expected response to selection in profit is equivalent, yet the relative weighting (and thus expected responses to selection) on the different components of the breeding goal may differ subtly. This is depicted in Figure 6 where the straight line represents an axis of equal expected profit 
response to selection. Point $\mathrm{X}$ and $\mathrm{Y}$ therefore should be equally profitable yet the expected response to selection on the input traits at point $\mathrm{Y}$ is almost double that of the breeding goal represented at point $X$ while the expected responses to selection for the output trait is only approximately $20 \%$ less. Such changes may be the difference between a breeding goal being accepted by industry or not.

A final consideration in the development of breeding goals is the definition of the trait used in the breeding goal. There is an on-going debate on whether RFI or feed intake should be included in the breeding goal for dairy and beef cattle. If appropriately undertaken, and the performance traits included in the regression for the generation of RFI are also included in the breeding goal, then both approaches are equivalent (Kennedy et al., 1993). Table 1 describes some of the advantages and disadvantages of including either feed intake or RFI in a breeding goal. The decision on which strategy to adopt may vary depending on how it will be eventually used and breeders' understanding of the different concepts (Wulfhorst et al., 2010). More importantly however is that the policy of selection for lower feed intake (or RFI) must be undertaken within the context of a holistic breeding objective. Energy balance and RFI, for example, are strongly positively correlated (McParland et al., 2014) and therefore selection for reduced RFI (or DMI while also selecting for increased production) will thrust the cow into more severe negative energy balance which will have disastrous repercussions for animal well-being and reproductive performance (Beam and Butler, 1999; Collard et al., 2000), and thus profit.

\section{Strategies to achieve genetic gain - what do we need?}

Dairy cow breeding programs are currently undergoing a paradigm shift with the widespread incorporation of low-cost genomic information into national genetic evaluations (Hayes et al., 2009; Spelman et al., 2013). The exploitation of this genomic information is resulting in more rapid genetic gain but also offers exciting new opportunities to increase performance further for a wider range of traits, especially if undertaken in conjunction with other (developing) technologies. All national dairy cow breeding goals in Holsteins constituted solely of milk production traits prior to the mid 1990's. Almost all dairy cow breeding goals now include other functional traits, in particular reproductive performance and animal health (Miglior et al., 2005). The relative emphasis on these traits differ by production system. Missing suites of traits from most, if not all, breeding goals include product quality, feed intake, and environmental footprint. Animal health is also poorly represented in most dairy cow breeding goals. The earlier discussions on the ideal cow for the future suggest that national cow breeding objectives are sub-optimal. Strategies exist, however, to rectify this. This section will particularly focus on strategies to achieve gains in these suites of traits. 
402

403

404

405

406

407

408

409

410

411

412

413

414

415

416

417

418

419

420

421

422

423

424

425

426

427

428

429

430

431

432

433

434

435

Producers will only record or pay for a phenotype if 1) it helps them improve herd profitability through the exploitation of greater knowledge, 2) they are financially incentivised to do so, 3) they are legally required to do so or participation in a scheme (e.g., quality assurance scheme) requires them to do so, or 4) if they are simply curious or have a desire to help achieve national objectives.

Access to a biological sample (i.e., milk) approximately twice daily provides huge potential opportunities for routine phenotyping of dairy cows. Developments and mining of transcriptomic, metabolomic and proteomic information can be used to identify indicators of the biological state of the cow which can subsequently be incorporated into targeted phenotyping tools. Heritable genetic variation is known to exist for the milk metabolome (Wittenburg et al., 2013) and proteome (Schopen et al., 2009). Milk mid-infrared (MIR) spectroscopy has recently been advocated as a useful tool to predict milk quality attributes (Soyeurt et al., 2011, 2012), cow energy balance (McParland et al., 2011), feed intake (McParland et al., 2011), feed efficiency (McParland et al., 2014), methane emissions (Dehareng et al., 2012) and milk urea nitrogen (Godden et al., 2000). Because MIR is routinely used to quantify milk fat, protein and lactose concentration on all milk recorded cows, the marginal cost of implementing prediction equations for other milk and animal characteristics is negligible once accurate prediction equations have been developed. Milk MIR therefore could be a very useful tool supporting the inclusion of novel traits reflecting milk quality, feed intake and efficiency, and environmental footprint in futuristic breeding goals. Absorption of light in the MIR regions corresponds to fundamental bands of molecular vibrations, whereas absorptions in near infrared (NIR) region correspond to overtones and combinations of these fundamental bands (Williams and Norris, 1987). Near-infrared spectroscopy however is more amenable to in-line measurement and thus could possibly also be useful in the low-cost, rapid and routine measurement of these quality and animal characteristics at each milking for each animal.

The future may require producers to be (financially) incentivised to record novel traits (e.g., feed intake) as the benefits of the information to the producer may not be immediately recognised. The cost-benefit of embarking on such a phenotyping strategy must however be appropriately quantified taking cognisance of alternative, lower-cost predictors including the example of milk MIR already discussed. The prediction accuracy for the goal trait does not need to be near unity. The genetic correlation between milk protein yield and calving interval (i.e., reproductive performance) in dairy cattle was calculated by Berry et al. (2014b) in a meta-analysis of eight studies to be 0.50 . Despite this, considerable (unintentional) dis-improvement in reproductive performance was achieved as an artefact of breeding strategies for increased production. Therefore, predictor traits correlated with the goal trait are useful in breeding goals; the reliability of the genetic evaluations of the goal 
trait however will never be greater than the square of the correlation with the predictor trait unless (phenotypic or genomic) information on the goal trait also exists. As previously discussed, inclusion of a (predicted) goal trait with low reliability will not impact greatly on the genetic gain in the other traits. Using feed intake in growing heifers as a predictor of feed intake of cows (Macdonald et al., 2014) could be a useful strategy for including feed intake in lactating cows in the breeding goal since disruption to normal routine for the measurement of feed intake is likely to have less impact in growing heifers than lactating cows.

Selection index theory can be used to combine several predictor traits in a multiple regression approach to predict the goal trait. Berry and Crowley (2013) using information on four commonly recorded performance traits within a selection index framework, reported that $89 \%$ of the genetic variation in feed intake in lactating dairy cows could be explained. Berry and Crowley (2013) proceeded to suggest that relatively simply implementable technologies like sensors at the feed bunk to measure feeding activity, or measurement of heat loss, could aid in predicting some of the remaining unexplained variation. The marginal benefit in accuracy of selection from measurement of the gold standard feed intake phenotype may actually be low relative to the cost; this needs to be quantified.

Considerable research is also underway on more refined measures of reproductive performance (Carthy et al., 2013; Walsh et al., 2014) as a means of increasing the heritability of reproductive performance. As previously alluded to however, it is not heritability per se which is important, it is genetic gain. Therefore if the more heritable reproductive traits are not easily amenable to large scale phenotyping, or incur a cost of phenotyping, then a benefit to such endeavours may not exist. The exception is if the heritability of the novel reproductive phenotypes is considerably larger, eliminating the necessity for phenotyping on a large population of animals. Furthermore, a more heritable phenotype may be advantageous in the selection of heifers for retention in a herd since the heritability is a reflection of how closely the genotype reflects the phenotype of an animal; the correlation between the observed phenotype and unobserved breeding value of an animal is the square root of the heritability.

\section{Genomics}

Genetic evaluations and genomic evaluations to date have unashamedly exploited a "black box" approach (Hill, 2010) where knowledge of the underlying genomic architecture governing phenotypic differences among animals was unknown. The progress however in all species has been immense (e.g., https://www.cdcb.us/eval/summary/trend.cfm). Weaknesses of quantitative genetics approaches based on exploiting knowledge on the expected relationships among animals include 
470 (Berry et al., 2011b): 1) the phenotype measured contains error (i.e., low heritability trait), 2) the 471 phenotype may not be measurable in both genders (e.g., milk yield in dairy cattle), 3) adult 472 performance cannot be measured in juveniles although it can be predicted and some traits like 473 longevity require a long time horizon to measure, 4) the animal may need to be sacrificed to obtain the 474 phenotype, 5) antagonistic genetic correlations between traits of interest cannot be easily resolved, 475 especially in young animals, and 6) genotype by environment interactions may exist, which may 476 complicate the statistical analysis. Furthermore, the estimation of accurate breeding values requires 477 the use of large and expensive breeding schemes such as progeny testing. Exploitation of genomic information in breeding strategies can aid in overcoming some of these shortcomings thus achieving 479 the cow of the future more rapidly. Because genomic information is available from birth, there is no 480 longer the requirement to wait several years until the female dairy animal start lactating, a further several years to obtain a phenotype for longevity, and also several years for the beef merit of the cow herself or her descendants to be observed. Genomic information is particularly useful in the generation of estimated breeding values for novel traits such as milk quality, feed intake, environmental footprint and animal health. Genomic information, however, for the foreseeable future will not negate the requirement of routine phenotypic information on these traits to achieve high accuracy of selection.

One of the main complications hindering rapid genetic progress in dairy cattle is the genetic antagonisms (Berry et al., 2011a; Berry and Crowley, 2013; Berry et al., 2014b) between output traits (i.e., milk production) and cost of production traits (i.e., health and fertility). Genetic correlations are a manifestation of either the same genomic mutation affecting both traits (termed pleiotropic effect) or different genomic mutations affecting both traits but tending to, on average, be inherited together (i.e., linkage). Selection affects genetic correlations, and if selection has been for improvements in both traits (e.g., milk production to feed new born and reproduction success to generate the next generation) the correlation is expected to become unfavourable (Falconer and Mackay, 1996), as currently observed in dairy cattle (Berry et al., 2014b). This is because the pleiotropic alleles acting favourably on both characteristics will become quickly fixed under selection; these alleles will thus contribute little to the variation or the covariance between the two characters. Alleles that affect both animal characteristics in opposing direction will remain in intermediate frequencies and therefore contribute more to the covariance between the traits; this also however implies little response to selection (Falconer and Mackay, 1996). Because rapid selection for increased milk production and reproductive performance is successful (Berry et al., 2014b), this suggests that considerable exploitable covariance still exists which could be due to pleiotropy or linkage. Exploitation of genomic information can aid in elucidating the genomic architecture underlying estimated genetic correlations; the component of the antagonistic correlation attributable to linkage may be resolved 
between favourable performance characteristics and unfavourable reproductive performance. Such an approach is particularly important for example for traits like feed intake and milk production where the goal is to change the positively correlated traits (Berry and Crowley, 2013) in opposite directions.

Genomic information is currently included in national dairy cow genetic evaluations using, in most cases, an unsupervised statistical approach; this approach is commonly termed genomic selection (Meuwissen et al., 2001) and the practicalities of implementing genomic selection for cattle has been discussed in detail elsewhere (VanRaden, 2008; Hayes et al., 2009; Calus, 2010). Many studies are on-going in search of the underlying causal mutations affecting phenotypic performance. The justification for such endeavours are usually to breed better animals through more informed (i.e., supervised) breeding schemes or "genotype building" (Dekkers and Hospital, 2002). Access to large databases of sequence data, once accompanied by large quantities of associated accurate phenotypes, will expedite the process. Studies have nonetheless been successful in detecting genomic regions harbouring unfavourable (e.g., lethal) mutations using just genomic information without necessarily associated phenotypic information (VanRaden et al., 2011). Detection of genomic variants that affect a large proportion of the genetic variation will remain a considerable and expensive endeavour. Moreover, even if allelic variation underlying a large proportion of the genetic variation is detected, this still represents just a small proportion of the phenotypic variation for low heritability traits. Many other potential outlays for knowledge of the underlying causal mutations and associated genes or gene networks therefore must be considered (Figure 7) which can be used to generate and manage the cow of the future.

\section{Genomics and precision mating}

Dairy cattle breeders have traditionally concerned themselves with the exploitation of additive genetic merit of individuals, because it is the additive allelic effects which are transmitted directly across generations. Non-additive genetic variation (i.e., inter- and intra-locus interactions) also contribute to the phenotypic variance (Wall et al., 2005; Sun et al., 2013) and has been successfully exploited through crossbreeding by, in particular, the New Zealand dairy industry (Lopez-Villalobos et al., 2000). Heterosis from the mating of two individuals is due to intra-locus effects (i.e., dominance) and inter-locus effects (i.e., epistasis). Therefore, the total genetic merit of an animal is a function of its additive genetic merit (i.e., estimated breeding value), dominance merit, and epistasis merit. The number of possible epistastic interactions in the genome is unwieldy but can be partly resolved as more causative mutations are detected. Locus-specific dominance effects can however be estimated simultaneously with allelic additive genetic effects ( $\mathrm{Su}$ et al., 2014). The predicted probability of the genotype of the progeny from a mating can be determined from the respective genotypes of the parents; for example, the predicted probability of a homozygous, heterozygous, and 
541 opposing homozygous genotype in the progeny of heterozygous parents is $0.25,0.50$ and 0.25 , 542 respectively. The merit of each locus genotype (i.e., additive genetic effect plus dominance effect for 543 heterozygous state) can then be summed across the predicted probability of each genotype to generate 544 a total genetic merit of an individual. Summed across all traits in the breeding goal, such information 545 can be used to identify the specific combining ability for an individual mating or the general 546 combining ability of a particular animal (e.g., bull) when mated to another group of animals (e.g., cow 547 herd). Such calculations encapsulate both mate complementarity and heterosis effects. known to impact animal performance (Smith et al., 1998; McParland et al., 2007). The inbreeding level of an animal, or coancestry between a pair of individuals, has heretofore been calculated from pedigree where it is assumed that full-sibs for example, share, on average, half their genome identical by descent (assuming the parents are not inbred). The actual proportion of the genome shared by fullsibs (same principle for other relatives) can differ; the standard deviation around this expectation is four percentage units in humans (Visscher et al., 2006). Genomic information can therefore be used to more accurately quantify the genomic relationships among animals (Pryce et al., 2012). For example it is theoretically possible (but extremely unlikely) that two full sibs from non-inbred parents can be completely unrelated; similarly an individual can be completely unrelated to one of its grandparents. Although the examples given are extreme examples and highly unlikely, it does emphasise that mating of traditionally thought of "highly related" animals may not result in high levels of inbreeding. This is particularly true at the individual locus level where the presence of lethal or unfavourable mutations (VanRaden et al., 2011) within a family can be controlled through designed matings without the necessity for blanket culling of carrier animals.

\section{Combined genomics and reproductive technologies strategies}

Reproductive technologies have a huge potential role in increasing the annual rate of genetic gain in dairy cattle mainly through increased intensity of selection (i.e., numerator) and reducing the generation interval (i.e., denominator). In reality there are four selection pathways influencing population genetic gain:

$$
\Delta \mathrm{G}_{\mathrm{YR}}=\frac{\left(\mathrm{i}_{\mathrm{SS}} \cdot \mathrm{r}_{\mathrm{SS}}+\mathrm{i}_{\mathrm{SD}} \cdot \mathrm{r}_{\mathrm{SD}}+\mathrm{i}_{\mathrm{DS}} \cdot \mathrm{r}_{\mathrm{DS}}+\mathrm{i}_{\mathrm{DD}} \cdot \mathrm{r}_{\mathrm{DD}}\right) \cdot \sigma_{\mathrm{G}}}{\mathrm{L}_{\mathrm{SS}}+\mathrm{L}_{\mathrm{SD}}+\mathrm{L}_{\mathrm{DS}}+\mathrm{L}_{\mathrm{DD}}}
$$

Where $\Delta \mathrm{G}_{\mathrm{YR}}$ is annual genetic gain, $i_{* *}$ is the standardised selection intensity for the $* *$ pathway, $\mathrm{r}_{* *}$ is the accuracy of selection for the ${ }^{* *}$ pathway, $\sigma_{\mathrm{G}}$ is the genetic standard deviation $\mathrm{L}_{* *}$ is 571 the generation interval for the ** pathway; the pathways SS, SD, DS and DD represent sire-to-sire, 572 sire-to-dam, dam-to-sire and dam-to-dam, respectively. Because genomic information can be used to 
generate an accurate prediction of the genetic merit of an animal at birth, one of the current limiting factors in the sire to produce progeny pathway is the age at which sufficient high quality semen can be obtained from young bulls and used in the population without compromising reproductive performance. This requires research on optimal pre- and post-pubertal management strategies of bulls as well as optimum cryopreservation and management strategies of the semen.

Cow natural reproductive rate limits the annual number of progeny per cow. Advances in ovum pick up and in vitro fertilisation techniques circumvent the necessity to wait for sexual maturity of potential dams thereby reducing the dam to produce progeny generation interval and increasing overall annual genetic gain. These approaches, coupled with multiple ovulation embryo transfer and embryo genotyping (Humblot et al., 2010), can also be used to reduce further the generation interval of the dam to progeny pathway while also increasing the respective selection intensity; such processes can also increase the selection intensity of the sire to progeny pathways.

To accelerate genetic gain, low cost semen sexing or gender-biasing technologies producing normal conception rate are required. Not alone will access to sexed semen improve genetic progress, but it can also improve animal welfare by reducing the incidence of dystocia in dairy cattle where (lighter) females are generally sought after. In addition, productivity could be increased, and the environmental impact reduced by having less productive or unwanted male animals.

\section{Combined genomics and management strategies}

Pharmocogenomics is the study of how the response to medicinal intervention is affected by the genome of the individual; the outcomes from this discipline facilitate the development of tailormade health programs for individuals differing in their underlying genome. For example, it may be decided to use dry cow therapy only on cows with a greater genomic risk of succumbing to udder infection in the following lactation. Nutrigenomics is the study of the effect of nutrition on gene expression, or in other words, the effect of the genome of the animal on response to alternative nutritional supplements. On-going dairy cow breeding programs have, and continue to take advantage of nutrigenomics at the macro level by selecting, for example, animals in confinement production systems that respond more to concentrate input. Controlled experiments have clearly showed than animals of superior genetic merit for milk production (generally of North Amercian ancestry) yield a greater milk production response to concentrate input compared to animals of lower genetic merit for milk production (Dillon et al., 2006). Genomics will facilitate more accurate identification of suitable animals for different production systems. I define reprogenomics here as the study of how the genome of the animal affects its response to alternative reproductive treatments (e.g., oestrus synchronisation treatments) or in other words the tailoring of reproductive treatments (if required) to the genome of 
the individual cow. Also included in this could be the receptiveness of individual cows to sexed semen; no information exists on whether genetic predisposition of individual cows to conception/pregnancy with sexed semen versus conventional semen exists although heritable genetic variation in sex ratio is known to exist (Berry et al. 2011b). It is unlikely, however, that any single mutation or small number of mutations will control a large proportion of the genetic variation in response to medicinal, nutritional or reproductive intervention in cattle and thus such strategies 1) will firstly require a huge amount of data to quantify the genetic by environmental effects, 2) segregation of animals for different management protocols will still have to be taken at the macro (i.e., estimated genetic value) level, albeit with greater accuracy to achievable heretofore.

\section{Sentinel herds}

Lessons from the past dictate that performance of genetically elite animals for a breeding goal should be continuously monitored and compared to lower genetic merit animals. Elucidation of any deleterious impacts of selection is arguably best achieved under controlled environments in a limited population where more detailed, or more expensive measurements, can be routinely undertaken. Moreover, health events are usually measured once the animal is in a clinical state but observations at the sub-clinical level can be used as an early alert of the long-term consequences of selection. Detailed -omic technologies (e.g., transcripomics, metabolomics, proteomics) undertaken on different biological samples from a limited number of animals can be extremely beneficial to predict what the likely consequences of selection are several generations hence. These sentinel herds are different to nucleus herds since they must also consist of a control group for comparative purposes but also some of the interventions required to decipher the impacts of selection (e.g., biopsies, infection with pathogens) may impact animal performance which will subsequently impact the estimated genetic merit of the animal. Although including contemporary group in the genetic evaluation model may aid in eliminating these effects, the possible carryover of effects and interactions between effects may bias the genetic evaluations. While sentinel herds are expensive to operate, they should be viewed as an important insurance policy for breeding programs.

\section{Breeding landscape of the future?}

The rapid advancements in '-omic' technologies and reproductive technologies necessitates a reassessment of modern-day breeding programs. Individual breeders in some countries can now receive genomic evaluations for their individual bulls, and therefore can obtain accurate estimates of genetic merit for routinely measured traits for tens of dollars compared to several thousands of dollars 
prior to the implementation of genomic selection. AI breeding companies must therefore identify additional added value for their bulls over and above the obvious like selling quality assured semen as well as access to sexed semen. Another value added resource may be accurate genetic/genomic evaluations for difficult to measure traits not already included in the national breeding objectives and thus not available to competing AI companies and breeders.

Although international sharing of phenotypic (Berry et al., 2014a) and genomic (Pryce et al., 2014) information for the derivation of international genomic evaluations of expensive to measure traits like feed intake is a plausible strategy, high accuracy of selection for the component of feed intake net of predictor traits is unlikely to be achievable. Furthermore, large scale phenotyping for gold standard feed intake measures in commercial herds is unlikely. Therefore, it is likely that the number of performance (or progeny) test centers may increase. Because the heritability of feed intake in lactating dairy cow is relatively high ( 0.10 to 0.54 ; Berry et al., 2007; Berry et al., 2014a; Veerkamp and Thompson, 1999), not many records are required to achieve high accuracy of selection. The reliability of a univariate genetic evaluation for feed intake where the animal itself has a feed intake observation (ignoring parental contribution) is the heritability; this is likely to be greater with the incorporation of genomic information once the reference population to estimate the allele effects is large and related to the candidate population (Habier et al., 2007; Pszczola et al., 2012). Only two studies have attempted to estimate the genetic correlation between feed intake in growing females and lactating dairy cows (Nieuwhof et al., 1992; Berry et al., 2014a); the genetic correlation is 0.67 to 0.74. Within a nucleus herd environment it may therefore be possible to phenotype the cow for feed intake during lactation. These data could be used to generate genomic evaluations for feed intake on candidate bulls which could be supplemented with actual feed intake records on the candidate bull itself during pre-pubertal growth; the feeding regime imposed should not affect subsequent semen production or quality. Moreover, consideration should be taken on the timing of the performance test relative to puberty, as bulls that reach puberty during the test may be expected to eat more and may subsequently be viewed as being poorly efficient. Methane emissions could also be simultaneously measured on all animals.

Consideration could also be given to measurement of novel traits on siblings; depending on the phenotype, it may be possible to measure performance of the entire group rather than individually thereby saving resources. Full or half-sib groups can be generated using MOET and some of the siblings sacrificed for phenotyping. An example of such an approach may be the inoculation of fullsib or half-sib males with pathogens and the animal response(s) measured; such approaches are successfully implemented in genetic evaluations of disease resistance in aquaculture (Ødegård et al., 2011). Although the maximum reliability achievable using traditional quantitative genetics from measurement on full-sibs (half-sibs) is $0.50(0.25)$, genomic predictions derived from the phenotyped siblings could aid in achieving considerably higher accuracy of selection. This design is particularly 
useful as the reference population would be clearly related to the candidate population thereby achieving a high accuracy of genomic prediction (Habier et al., 2007; Pszczola et al., 2012).

Intellectual property leakage is of increasing concern among breeding companies who invest considerable resources in the development of a genetically elite product (e.g., breeding values for novel traits). Semen from these genetically elite bulls, however, may be used by competitors to generate bull descendants with the elite characteristics. Figure 8 shows how a base population can be rapidly upgraded to another (elite) population; within 3 generations the upgraded population contains, on average, $87.5 \%$ of the elite population which increases to $93.75 \%$ in generation 4 . This process can be intensified through the exploitation of reproductive technologies (i.e., ovum pickup plus in vitro fertilisation) and the rate of upgrading can also be increased through exploitation of genomic information to retain animals with a greater proportion of the elite genetic line. Other than the necessity of invoking legislation to prevent such efforts, the marketing of female-only sexed semen will retain ownership of the proprietary lines, ensuring the necessary return on investment (at least in the short to medium term). Even if a male calve results, it possess only half the genome of the elite line and its progeny only, on average, a quarter of the genome.

Artificial insemination has revolutionised dairy cattle breeding since its wide-spread adoption. AI, however, has only resulted in increased selection intensity in the sire to progeny selection pathway. Considerable gains in selection intensity, and thus genetic gain, could be achieved by applying similar principles to the dam to progeny selection pathways. This would involve a large scale generation of embryos or female progeny for sale to elite breeders which in turn could act as multiplier herds for commercial producers. Parents or siblings of the embryos could be phenotyped for novel traits and genomic predictions derived; the embryos could be genomically screened and sexed and the price requested tiered based on genetic merit. Moreover, favourable epigenetic effects could be sought by implanting the embryos into unstressed surrogate dams.

\section{Conclusions}

The first step in breeding for the cow of the future is to agree on the characteristics that describe that ideal cow and the relative importance of each of those characteristics. Because of genetic antagonisms, it may not be possible to achieve ideal performance for each characteristic. Acquisition of phenotypic data remains one of the key components for achieving high accuracy of selection and thus genetic gain, even in the genomics era. Key suites of traits warranting immediate inclusion in dairy cow breeding goals include product quality, feed intake and efficiency, environmental footprint and animal health. 


\section{References}

711 Beam SW, Butler WR (1999) Effects of energy balance on follicular development and first ovulation in postpartum dairy cows. Journal of Reproduction and Fertility Supplement. 54, 411-424.

Bell MJ, Eckard RJ, Haile-Mariam M, Pryce JE (2013) The effect of changing cow production and fitness traits on net income and greenhouse gas emissions from Australian dairy systems. Journal of Dairy Science 96, 7918-7931

Berry DP, Bermingham M, Good M, More SJ (2011a) Genetics of animal health and disease in cattle. Irish Veterinary Journal 64, 5

Berry DP, Coffey MP, Pryce JE, de Haas Y, Lovendahl P, Krattenmacher N, Crowley JJ, Wang Z, Spurlock D, Weigel K, MacDonald K, Veerkamp R. (2014a) International genetic evaluations for feed intake in dairy cattle through the collation of data from multiple sources. Journal of Dairy Science 97, 3894-3905

Berry DP, Crowley JJ (2013) Genetics of feed efficiency in dairy and beef cattle. Journal of Animal Science 91, 1594-1613

Berry DP, Coughlan B, Enright B, Coughlan S, Burke M (2013) Factors associated with milking characteristics in dairy cows Journal of Dairy Science 96, 5943-5953

Berry DP, Harris BL, Winkelman AM, Montgomerie W (2005) Phenotypic associations between traits other than production and longevity in New Zealand dairy cattle. Journal of Dairy Science 88, 2962 - 2974.

Berry DP, Horan B, O'Donovan M, Buckley F, Kennedy E, McEvoy M, Dillon PG (2007) Genetics of grass dry matter intake, energy balance, and digestibility in grazing Irish dairy cows. Journal of Dairy Science 90, 4835-4845

Berry DP, Lee JM, Macdonald KA, Roche JR (2007) Body condition score and body weight effects on dystocia and stillbirths and consequent effects on postcalving performance. Journal of Dairy Science 90, 4201-4211

Berry DP, Kearney JF, Roche JR (2011b) Evidence of genetic and maternal effects on secondary sex ratio in cattle. Theriogenology $\mathbf{7 5}, 1039-1044$

Berry DP, Meaney WJ (2005) Cow factors affecting the risk of clinical mastitis. Irish Journal of Agricultural \& Food Research 44, 147-156

Berry DP, Meade K, Mullen MP, Butler S, Diskin MG, Morris DG, Creevey CJ (2011) The integration of omic disciplines and systems biology in cattle breeding. Animal 5, 493-505.

Berry DP, Wall E, Pryce JE (2014b) Genetics and genomics of reproductive performances in dairy and beef cattle. Animal 8, 105-121

Cabrera VE (2014) Economics of fertility in high-yielding dairy cows on confined TMR systems. Animal 8, 211-221.

Calus MPL (2010) Genomic breeding value prediction: methods and procedures. Animal 4, 157-164. 
Carthy TR, Berry DP, Fitzgerald A, McParland S, Williams EJ, Butler S, Cromie AR, Ryan D (2014) Risk factors associated with detailed reproductive phenotypes in dairy and beef cows. Animal 8, 695-703

Chillard Y, Ferlay A, Doreau M (2001) Effect of different types of forages, animal fat or marine oils in cow's diet on milk fat secretion and composition, especially conjugated linoleic acid (CLA) and polyunsaturated fatty acids. Livestock Production Science. 70, 31-48.

Coleman J, Berry DP, Pierce KM, Brennan A, Horan B. (2010) Dry matter intake and feed efficiency profiles of 3 genotypes of Holstein-Friesian within pasture-based systems of milk production. Journal of Dairy Science 93, 4318-4331

Collard BL, Dekkers JCM, Petitclerc D, Schaeffer LR (2000) Relationships between energy balance and health traits of dairy cattle in early lactation. Journal of Dairy Science 83, 2683-2690.

de Graaf T, Dwinger RH (1996) Estimation of milk production losses due to sub-clinical mastitis in dairy cattle in Costa Rica. Preventative Veterinary Medicine 26, 215-222.

Dehareng F, Delfosse C, Froidmont E, Soyeurt H, Martin C, Gengler N, Vanlierde A, Dardenne P (2012) Potential use of milk mid-infrared spectra to predict individual methane emission of dairy cows Animal 6, 1694-1701.

Dekkers JCM, Hospital F (2002). The use of molecular genetics in the improvement of agricultural populations. Nature Reviews Genetics 3, 22-32

Dillon PG, Berry DP, Evans RD, Buckley F, Horan B (2006) Consequences of genetic selection for increased milk production in European seasonal pasture based systems of milk production. Livestock Production Science 99, 141-158

Dohoo IR, Martin SW (1984) Subclinical ketosis: prevalence and associations with production and disease. Canadian Journal Comp Medicine. 48, 1-5.

Evans RD, Dillon PG, Buckley F, Berry DP, Wallace M, Ducrocq V, Garrick DJ (2006) Trends in milk production, calving rate and survival of cows in 14 Irish dairy herds as a result of the introgression of Holstein-Friesian genes. Animal Science 82, 423-433

Falconer DS, Mackay TFC (1996) Introduction to quantitative genetics. 4th ed. Longman, Essex, UK. FAO 2009. Declaration of the World Food Summit on Food Security, Rome, 16-18 November 2009. Rome: FAO. Available online at: ftp://ftp.fao.org/docrep/fao/Meeting/018/k6050e.pdf (verified 25 September 2010).

Gibson JP, Kennedy BW (1990) The use of constrained selection indexes in breeding for economic merit. Theoretical and Applied Genetics 80, 801-805. Incorporating heifer feed efficiency in the Australian selection index using genomic selection

Godden SM, Lissemore KD, Kelton DF, Lumsden JH, Leslie KE, Walton JS (2000) Analytic validation of an infrared milk urea assay and effects of sample acquisition factors on milk urea results. Journal of Dairy Science 83, 435-442 
Gonzalez-Recio O, Pryce JE, Haile-Mariam M, Hayes BJ (2014) Incorporating heifer feed efficiency in the Australian selection index using genomic selection. Journal of Dairy Science. 97, 38833893

Grummer RR (1991) Effect on feed on the composition of milk fat. Journal of Dairy Science 74, 3228-3243.

Habier D, Fernando R, Dekkers JCM (2007) The impact of genetic relationship information on genome-assisted breeding values. Genetics 177, 2389-2397

Hansen P, Ombler F (2009) A new method for scoring additive multi-attribute value models using pairwise rankings of alternatives. Journal of Multi-Criteria decision analysis. 15, 87-107.

Hayes BJ, Bowman PJ, Chamberlain AJ, Goddard ME (2009) Invited review: Genomic selection in dairy cattle: Progress and challenges. Journal of Dairy Science. 92, 433-443.

Hill WG (2010) Understanding and using quantitative genetic variation. Philosophical Transactions of The Royal Society B Biological Sciences. 365, 73-85.

Horan B, Dillon PG, Berry DP, O'Connor P, Rath M (2005) The effect of strain of Holstein-Friesian, feeding system and parity on lactation curves characteristics of spring-calving dairy cows. Livestock Production Science 95, 231-241

Humblot P, Le Bourhis D, Fritz S, Colleau JJ, Gonzalez C, Joly CG, Malafosse A, Heyman Y, Amigues Y, Tissier M, Ponsart C (2010) Reproductive Technologies and Genomic Selection in Cattle. Veterinary Medicine International. 2010, 192787

Johnson KA, Johnson DE (1995) Methane emissions from cattle. Journal of Animal Science. 73, 2483-2492.

Jury WA, Vaux HJ Jr. (2007) The emerging global water crisis: managing scarcity and conflict between water users. Advances in Agronomy. 95, 124.

Kennedy BW, van der Werf JHJ, Meuwissen THE (1993) Genetic and statistical properties of residual feed intake. Journal of Animal Science 71, 3239-3250.

Larroque H, Ducrocq V (2001) Relationships between type and longevity in the Holstein breed. Genetics Selection Evolution. 33, 39-39

Lopez-Villalobos N, Garrick DJ, Blair HT, Holmes CW. 2000. Possible effects of 25 years of selection and crossbreeding on the genetic merit and productivity of New Zealand dairy cattle. Journal of Dairy Science, 83, 154-163.

Macdonald KA, Pryce JE, Spelman RJ, Davis SR, Wales WJ, Waghorn GC, Williams YJ, Marett LC, Hayes BJ (2014) Holstein-Friesian calves selected for divergence in residual feed intake during growth exhibited significant but reduced residual feed intake divergence in their first lactation. Journal of Dairy Science 97, 1427-1435.

McHugh N, Fahey AG, Evans RD, Berry DP (2010) Factors associated with selling price of cattle at livestock marts. Animal 4, 1378-1389 
Mee JF, Berry DP, Cromie AR (2008) Prevalence of, and risk factors associated with, perinatal calf mortality in pasture-based Holstein-Friesian cows. Animal 2, 613-620

Mee JF, Berry DP, Cromie AR (2011) Risk factors for calving assistance and dystocia in pasturebased Holstein-Friesian heifers and cows in Ireland. The Veterinary Journal 187, 189-194

McParland S, Banos G, Wall E, Coffey MP, Soyeurt H, Veerkamp RF, Berry DP (2011) The use of mid-infrared spectrometry to predict body energy status of Holstein cows. Journal of Dairy Science 94, 3651-3661

McParland S, Lewis E, Kennedy E, Moore SG, McCarthy B, O'Donovan M, Butler ST, Pryce JE, Berry DP (2014) Mid-infrared spectrometry of milk as a predictor of energy intake and efficiency in lactating dairy cows. Journal of Dairy Science (In Press)

McParland S, Kearney JF, Rath M, Berry DP (2007) Inbreeding effects on milk production, calving performance, fertility, and conformation in Irish Holstein-Friesians. Journal of Dairy Science 90, 4411-4419

Meuwissen THE, Hayes BJ, Goddard ME (2001) Prediction of total genetic value using genome-wide dense marker maps. Genetics 157, 1819-1829.

Miglior F, Muir BL, Van Doormaal BJ (2005) Selection indices in Holstein cattle of various countries. Journal of Dairy Science 88, 1255-1263.

Miglior F, Sewalem A, Jamrozik J, Bohmanova J, Lefebvre DM, Moore RK (2007) Genetic analysis of milk urea nitrogen and lactose and their relationships with other production traits in Canadian Holstein cattle. Journal of Dairy Science 90, 2468-2479

Molden D (2007) Water for Food Water for Life: A Comprehensive Assessment of Water Management in Agriculture. International Water Management Institute, Battaramulla, Sri Lanka, Pages: 688.

Morison JI, Baker NR, Mullineaux PM, Davies WJ (2008) Improving water use in crop production. Philosophical Transactions of The Royal Society B Biological Sciences.12, 639-658.

Nielsen HM, Christensen LG, Groen AF (2005) Derivation of sustainable breeding goals for dairy cattle using selection index theory. Journal of Dairy Science 88, 1882-1890.

Nieuwhof GJ, van Arendonk JAM, Vos H, Korver S (1992) Genetic relationships between feed intake, efficiency and production traits in growing bulls, growing heifers and lactating heifers. Livestock Production Science 32, 189-202.

Ødegård, J, Baranski M, Gjerde, B Gjedrem T. 2011. Methodology for genetic evaluation of disease resistance in aquaculture species: challenges and future prospects. Aquaculture Research $\mathbf{4 2}$, 103-114.

O’Mara FP (2011) The significance of livestock as a contributor to global greenhouse gas emissions today and the near future. Animal Feed Science and Technology 166-167, 7-15. 
Passioura JB, Angus JF (2010) Improving Productivity of Crops in Water-Limited Environments. In Donald L. Sparks editor: Advances in Agronomy, Vol. 106, Burlington: Academic Press, 2010, pp.37-75.

Pryce JE, Hayes BJ, Goddard ME (2012) Novel strategies to minimize progeny inbreeding while maximizing genetic gain using genomic information. Journal of Dairy Science. 95, 377-388

Pryce JE, Johnston J, Hayes BJ, Sahana G, Weigel KA, McParland S, Spurlock D, Krattenmacher N, Spelman RJ, Wall E, Calus MPL (2014) Imputation of genotypes from low density (50,000 markers) to high density (700,000 markers) of cows from research herds in Europe, North America, and Australasia using 2 reference populations. Journal of Dairy Science 97, 17991811.

Pszczola M, Strabel T, Mulder HA, Calus MPL (2012) Reliability of direct genomic values for animals with different relationships within and to the reference population. Journal of Dairy Science 95, 389-400.

Rendel J, Robertson A (1950) Estimation of genetic gain in milk yield by selection in a closed herd of dairy cattle. Journal of Genetics 50, 1-8.

Roche JR, Berry DP (2006) Periparturient climatic, animal and management factors influencing the incidence of milk fever in grazing Systems. Journal of Dairy Science 89, 2775-2783

Rosegrant MW, Cai X, Cline SA (2002) Global water outlook to 2025, averting an impending crisis. A 2020 vision for food, agriculture, and the environment initiative. International food policy research institute (IFPRI) and international water management institute (IWMI).

Royal MD, Darwash AO, Flint APF, Webb R, Woolliams JA, Lamming GE (2000) Declining fertility in dairy cattle: changes in traditional and endocrine parameters of fertility. Animal Science 70, 487-501.

Schopen GCB, Heck JML, Bovenhuis H, Visker MHPW, van Valenberg HJF, van Arendonk JAM (2009). Genetic parameters for major milk proteins in Dutch Holstein-Friesians. Journal of Dairy Science. 92, 1182-1191.

Shalloo L, Cromie A, McHugh N (2014) Effect of fertility on the economics of pasture-based dairy systems. Animal 8, 222-231

Shalloo L, Dillon P, Rath M, Wallace M (2004) Description and validation of the Moorepark Dairy Systems Model (MDSM). Journal of Dairy Science 87, 1945-1959.

Smith LA, Cassell BG, Pearson RE (1998) The effects of inbreeding on lifetime performance of dairy cattle. Journal of Dairy Science 81, 2729-2737

Solomon S (2010) Water: the epic struggle for wealth, power, and civilisation. Harper Collins, New York, NY, USA.

Soyeurt H, Gillon A, Vanderick S, Mayeres P, Bertozzi C, Gengler N (2007) Estimation of heritability and genetic correlations for the major fatty acids in bovine milk. Journal of Dairy Science 90, 4435-4442 
Soyeurt H, Bastin C, Colinet FG, Arnould VM-R, Berry DP, Wall E, Dehareng F, Nguyen HA, Dardenne P, Schefers J, Vandenplas J, Weigel K, Coffey MP, Theron L, Detilleux J, Reding E, Gengler N, McParland S (2012) Mid-infrared prediction of lactoferrin content in bovine milk: potential indicator of mastitis. Animal 6, 1830-1838

Soyeurt H, Dehareng F, Gengler N, McParland S, Wall E, Berry DP, Coffey M, Dardenne P (2011) Mid-infrared prediction of bovine milk fatty acids across multiple breeds, production systems, and countries. Journal of Dairy Science 94, 1657-1667

Spelman RJ, Hayes BJ, Berry DP (2013) Use of molecular technologies for the advancement of animal breeding: genomic selection in dairy cattle populations in Australia, Ireland and New Zealand. Animal Production Science 53, 869-875

Steinfield H, Gerber P, Wassenaar T, Castel V, Rosales M, De Haan C (2006) Livestock's Long Shawdow. Environmental issues and Options. FAO Report. Rome: FAO. Available online at ftp://ftp.fao.org/docrep/fao/010/A0701E/A0701E00.pdf (verified 12 May 2012)

Sturaro E, Marchiori E, Penasa M, Ramanzin M, Bittante G (2013) Dairy systems in mountain areas in terms of farm animal biodiversity, milk production and destination and land use and landscape preservation. Livestock Science 158, 157-168.

Sun C, VanRaden PM, O'Connell JR, Weigel KA, Gianola D (2013) Mating programs including genomic relationships and dominance effects. Journal of Dairy Science. 96, 8014-8023.

Su G, Christensen OF, Ostersen T, Henryon M, Lund MS (2012) Estimating additive and nonadditive genetic variances and predicting genetic merits using genome-wide dense single nucleotide polymorphism markers. PLOSOne 7, e45293

United Nations Environmental Program (UNEP). 2008. Vital Water Graphics - An overview of the state of the World's Fresh and Marine Waters. $2^{\text {nd }}$ Ed UNEP, Nairobi, Kenya, Accessed March 10, 2012. http://www.grida.nl/publications/vg/water2/

USDA-NASS, Agricultural Resource Management Survey, 2011, Accessed February 22, 2012 http://www.ers.usda.gov/data/costsamdreturns/testpick.htm\#milkproduction

Van der Werf JHJ, van der Waaij LH, Groen AF, de Jong G (1998) An index for beef and veal characteristics in dairy cattle based on carcass traits. Livestock Production Science 54, 11-20.

VanRaden PM (2008). Efficient methods to compute genomic predictions. Journal of Dairy Science 91, 4414-4423.

VanRaden PM, Olson KM, Null DJ, Hutchison JL (2011) Harmful recessive effects on fertility detected by absence of homozygous haplotypes. Journal of Dairy Science. 94, 6153-6161.

Veerkamp RF, Thompson R (1999). A covariance function for feed intake, live weight, and milk yield estimated using a random regression model. Journal of Dairy Science 82, 1565-1573.

Visscher PM, Hill WG, Wray NR (2008) Heritability in the genomics era - concepts and misconceptions. Nature Reviews, Genetics. 9, 255-266. 
Visscher, PM, Medland SE, Ferreira MAR, Morley KI, Zhu G, Cornes BK, Montgomery CW, and Martin NG. 2006. Assumptions-free estimation of heritability from genome-wide identity-bydescent sharing between full siblings. Plos Genetics. 2, 241

Yatoo MI, Kumar P, Dimri U, Sharma MC (2012) Effects of climate change on animal health and diseases. International Journal of Livestock Research 2, 15-24.

Wall E, Simm G, Moran D (2010) Developing breeding schemes to assist mitigation of greenhouse gas emissions. Animal 4, 366-376.

Wall E, Brotherstone S, Kearney JF, Woolliams JA, Coffey MP (2005) Impact of nonadditive genetic effects in the estimation of breeding values for fertility and correlated traits. Journal of Dairy Science 88, 376-385

Walsh S, Buckley F, Berry DP, Rath M, Pierce K, Byrne N, Dillon PG (2007). Effect of breed, feeding system, and parity on udder health and milking characteristics. Journal of Dairy Science 90, 5767-5779

Walsh SW, Mossa F, Butler ST, Berry DP, Scheetz D, Jimenez-Krassel F, Tempelman RJ, Carter F, Lonergan P, Evans AOC, Ireland JJ. (2014) Heritability and impact of environmental effects during pregnancy on antral follicle count in cattle. Journal of Dairy Science. 97, 4503-4511

Williams P, Norris K (1987) Near-infrared Technology in the Agricultural and Food Industries. Am. Assoc. Cereal Chem., St. Paul, MN (1987)

Wittenburg D, Melzer N, Willmitzer L, Lisec J, Kesting U, Reinsch N, Repsilber D (2013) Milk metabolites and their genetic variability. Journal of Dairy Science. 96, 2557-2569.

Wulfhorst JD, Ahola JK, Kane SL, Keenan LD, Hill RA (2010) Factors affecting beef cattle producer perspectives on feed efficiency. Journal of Animal Science. 88, 3749-3758.

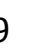

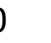

1

(1)

(1)

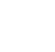


Table 1. Reasons in favor and against including dry matter intake (DMI) or residual feed intake (RFI) in a

DMI in the breeding goal

\begin{tabular}{|c|c|}
\hline For & Against \\
\hline Easy to explain and understand & Cannot easily identify efficient animals \\
\hline Economic value is relatively easy to calculate & May be mis-understood (positive EBV may be efficient) \\
\hline Amenable to customised indexes & Correlated with performance \\
\hline $\begin{array}{l}\text { Economic value on other components reflect reality in the } \\
\text { market place (e.g., fat:protein price ratio) }\end{array}$ & $\begin{array}{l}\text { Independent culling levels may be harmful to overall gain } \\
\text { Misinterpreted that negative EBV might imply poorer }\end{array}$ \\
\hline Good predictors available & performing animals \\
\hline $\begin{array}{l}\text { Higher "reliability" through selection index theory } \\
\text { May be less susceptible to genotype by environment } \\
\text { interactions (GxE) }\end{array}$ & \\
\hline
\end{tabular}

RFI in the breeding goal

For Against

Economic value is relatively easy to calculate

Can "easily" slot in to current breeding goals

(Theoretically) uncorrelated with performance

Relatively simple message (if not caught up in details)

Could materialize in faster genetic gain for efficiency
Difficult to explain technically

Low reliability (currently)

Possibly more susceptible to GxE

Selection index within a selection index

Sensible to select on something we do not understand?

(Never stopped us before!)

Mixed messages from "pro" and "against" camps

RFI in lactating animals (as currently defined) is not ideal

EBVs may change as the RFI model changes

Possibly correlated with fertility (so is DMI!) 


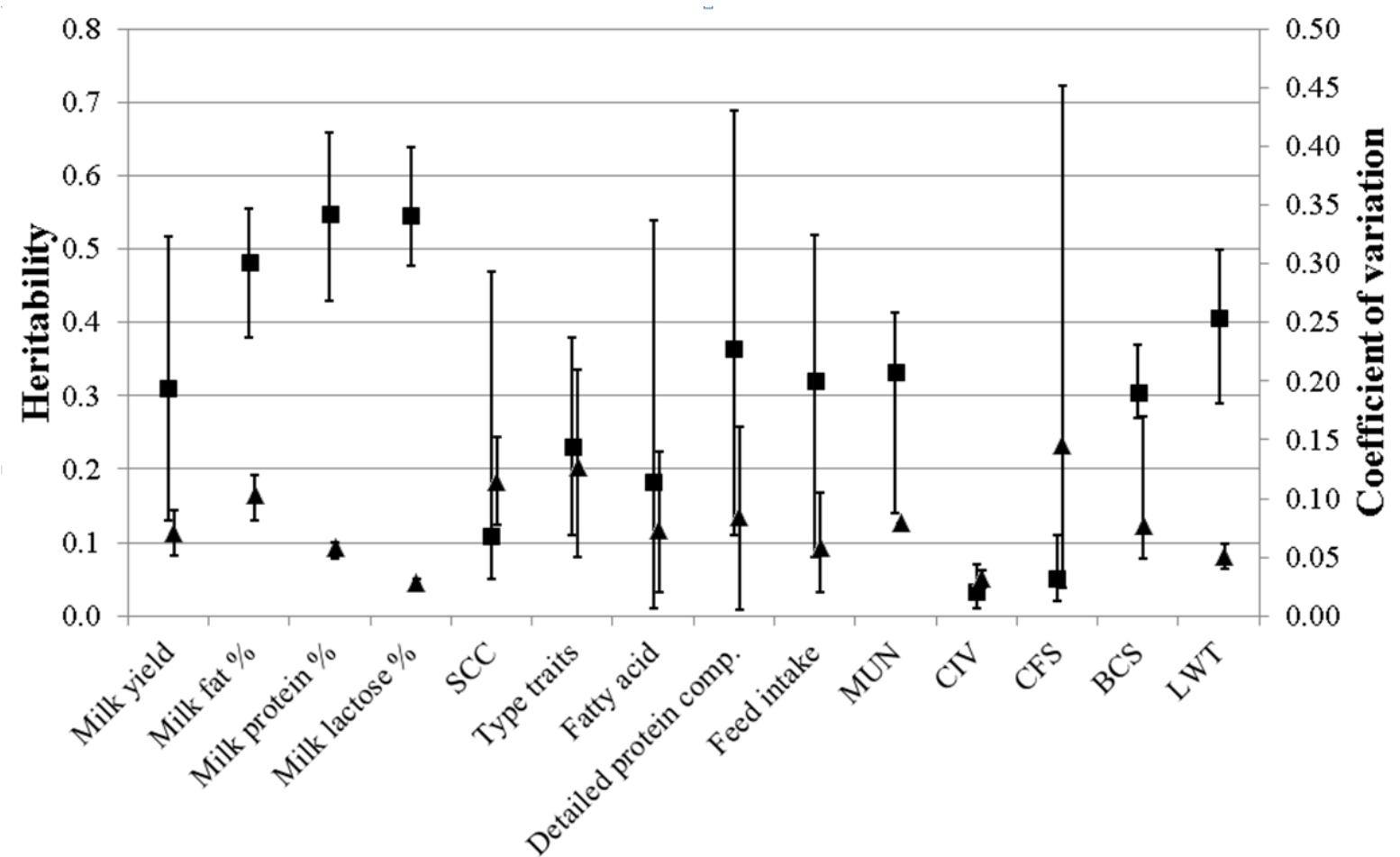

983

Trait

984 Figure 1. Mean heritability (squares) and coefficient of genetic variation (triangle) and variation

(represented by error bars) for a range of performance traits including somatic cell count (SCC), milk urea nitrogen (MUN), calving interval (CIV), calving to first service interval (CFS), body conditions 987 core (BCS) and live-weight (LWT)

988

989

990

991

992

993

994

995 


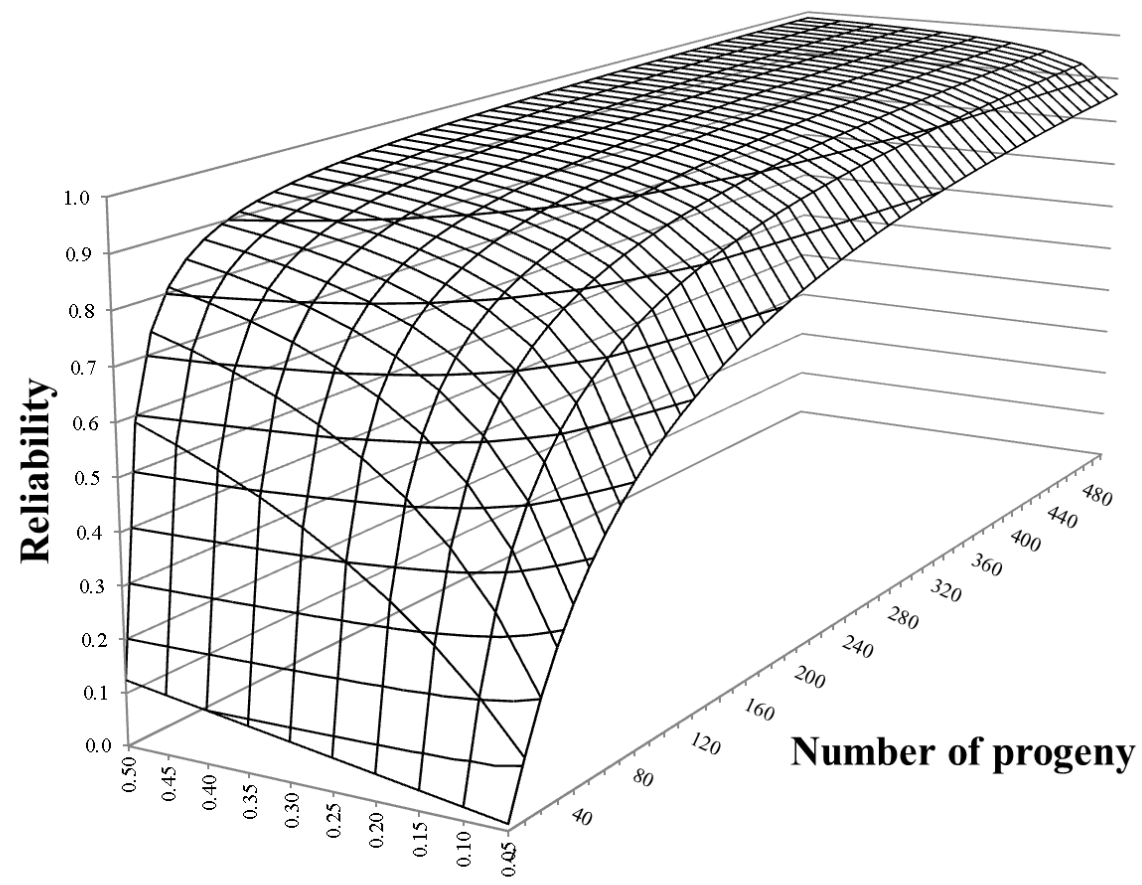

Heritabiity

997 998

999

1000

1001

1002

1003

1004

1005

1006

1007

1008

1009

1010 


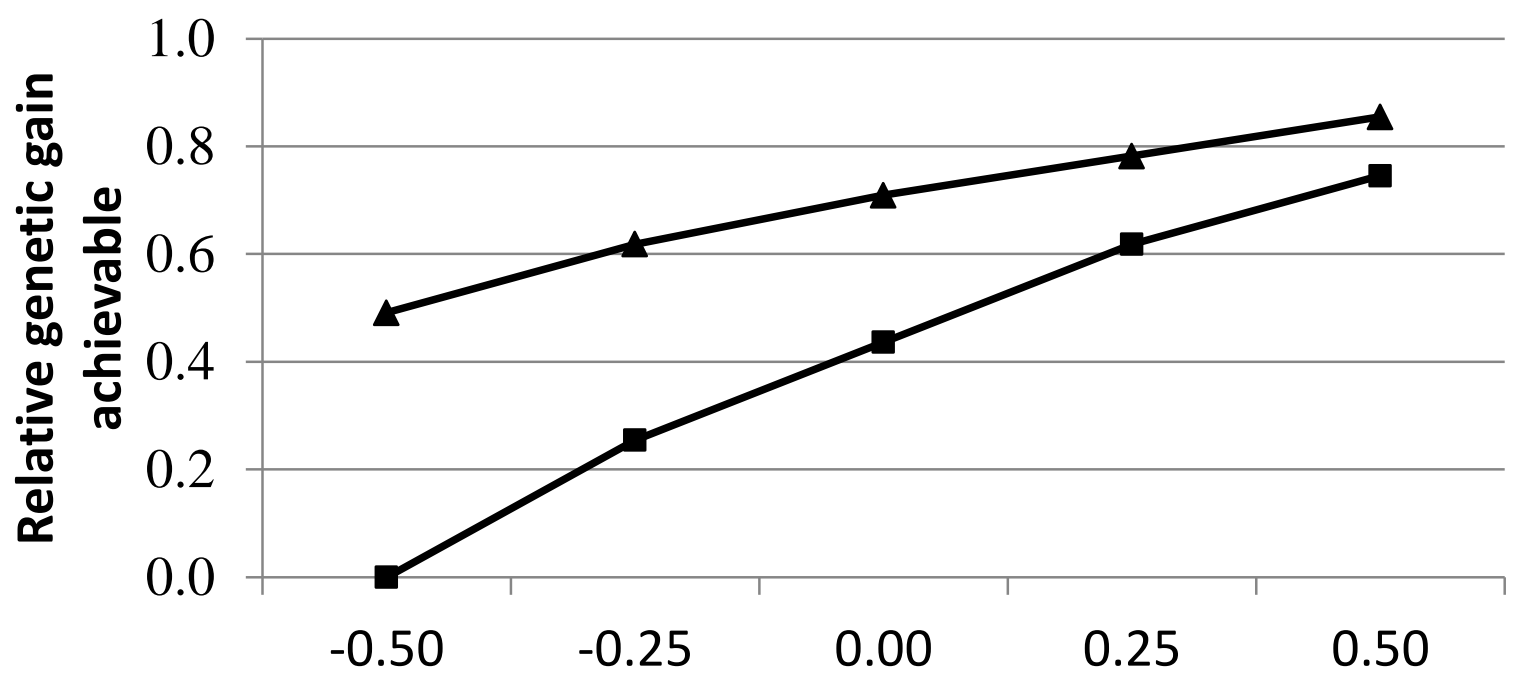

Genetic correlation between both traits

Figure 3. Expected genetic gain in a given trait in a two trait breeding goal with a second trait with the same genetic variance times economic weight as the first trait (triangle) or twice the genetic variance times economic weight of the first trait (squares) relative to selection solely on the trait itself; accuracy of selection for both traits was assumed to be 0.99 . 


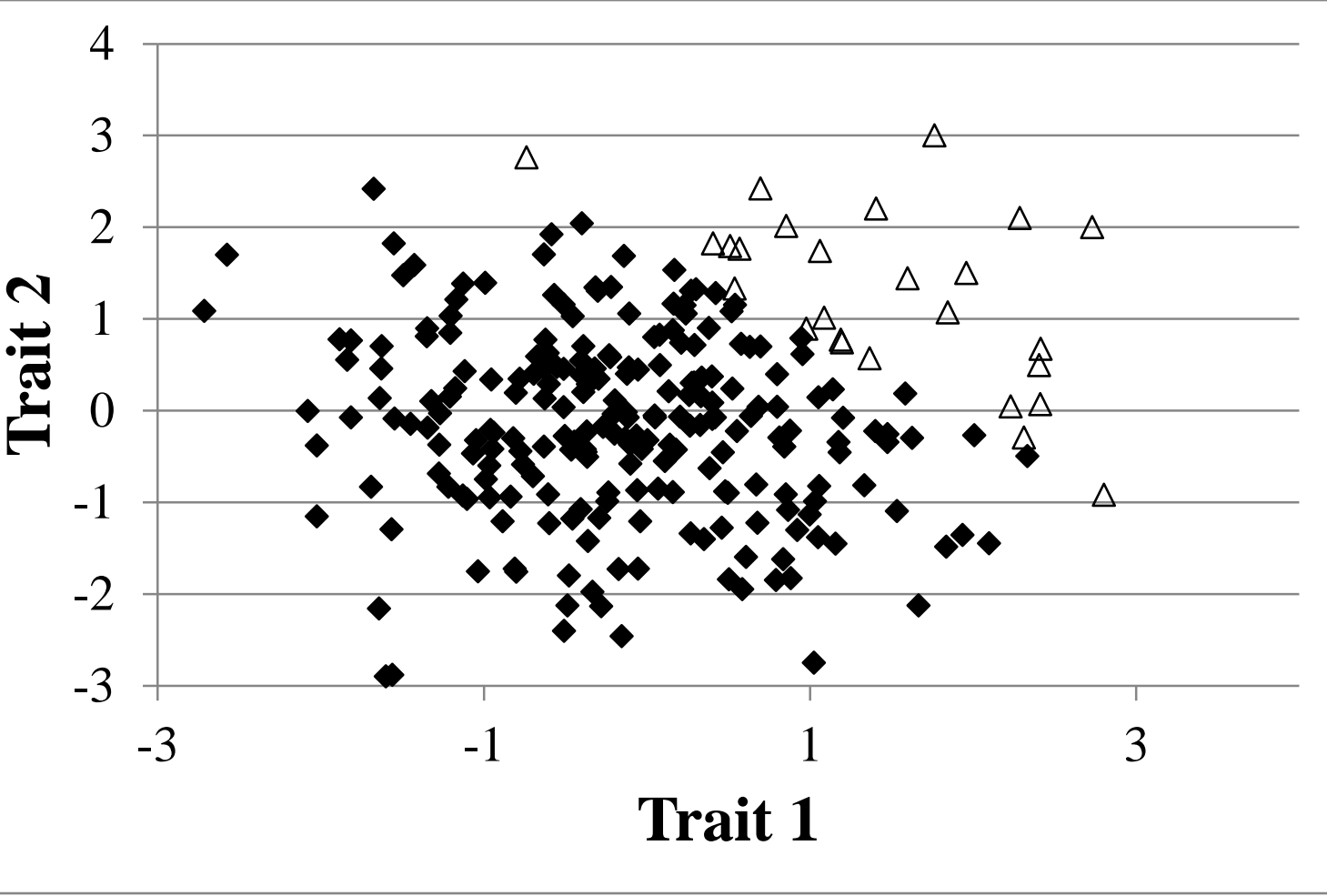

Figure 4. Scatter plot of two uncorrected traits each standardised to a normal distribution. Triangles

1031 represent the top $10 \%$ of animals ranked on a combination of both traits each with the same

1032 weighting.

1034

1035

1036

1037

1038

1039

1040

1041

1042 


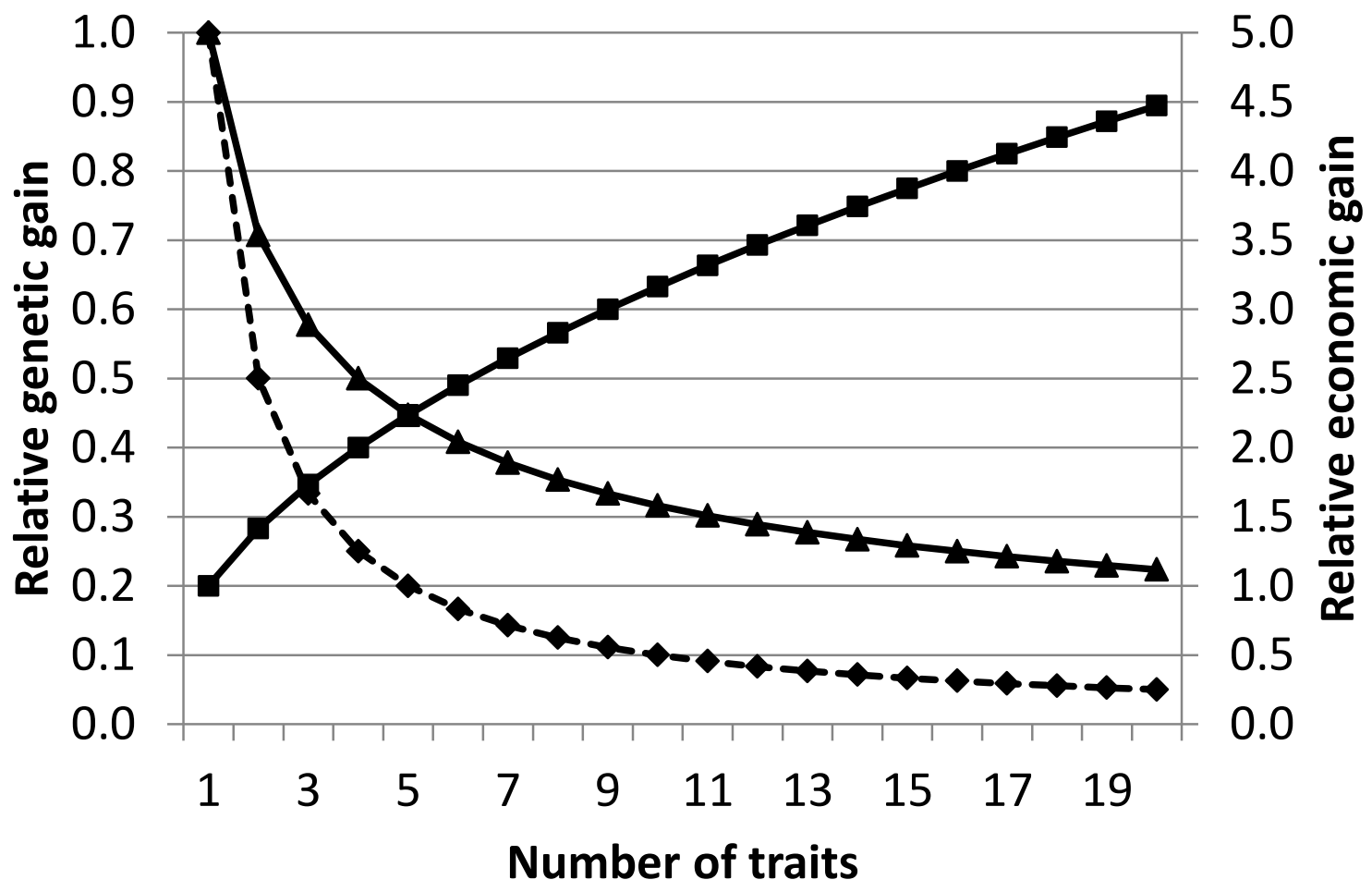

1044 Figure 5. Expected genetic gain for a given trait as the number of traits included in the breeding goal 1045 increases from one to 20 (triangle) assuming equal genetic variance, weighting and accuracy of selection for each trait as well as no covariance between any trait as well as the relative economic gain (squares; per index standard deviation unit) for the entire index assuming an equal economic weight of one on all traits. Also included is the calculated relative emphasis for a trait within the breeding goal differing in number of included traits.

1050

1051

1052

1053

1054

1055

1056

1057 


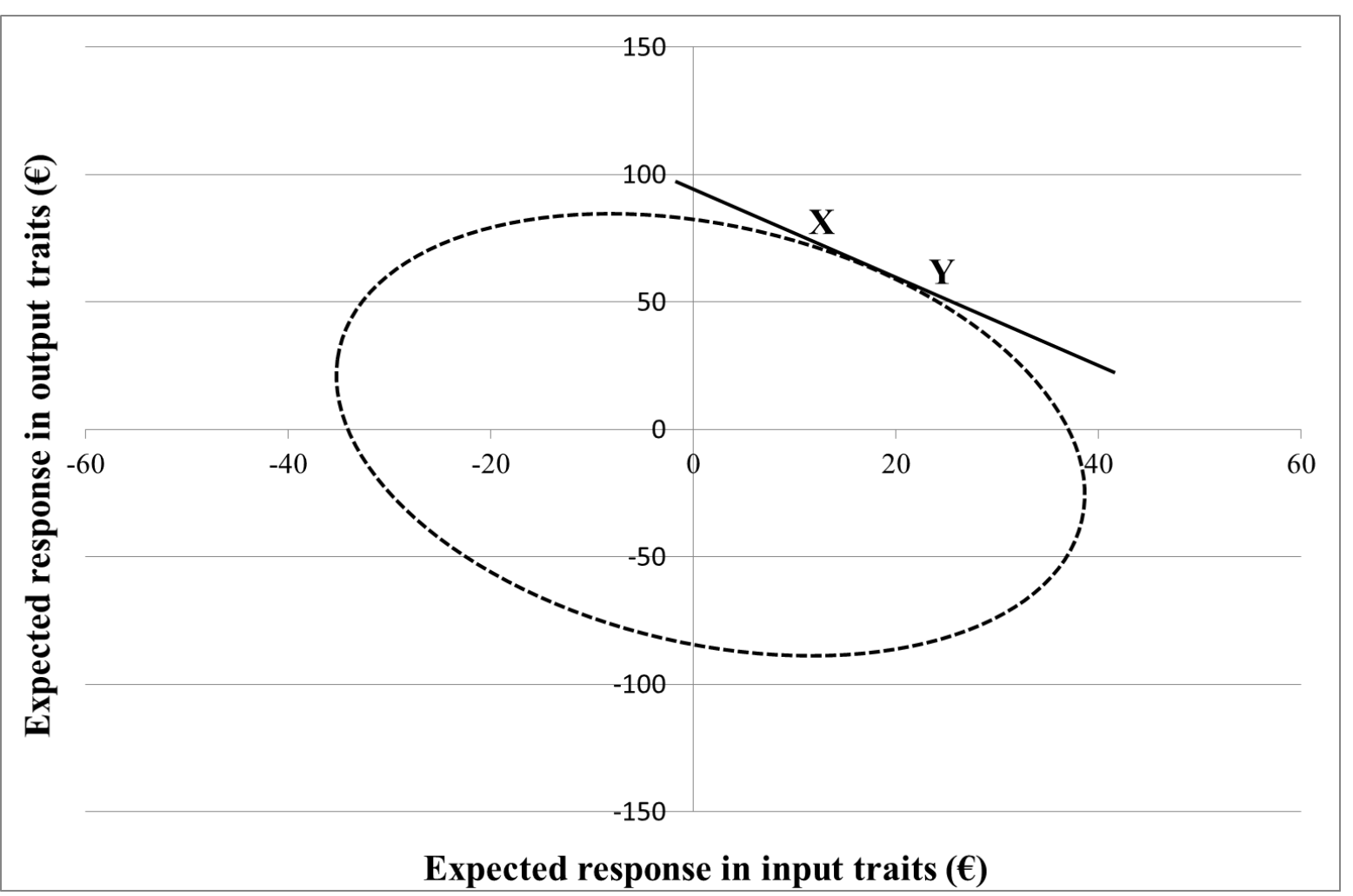

1059 Figure 6. Comparison of the effect of alternative breeding goals on input and output traits on expected 1060 responses in profit. Point $\mathrm{X}$ and $\mathrm{Y}$ will yield the same expected profit but relative expected responses 1061 for the input and output traits differ considerably. 


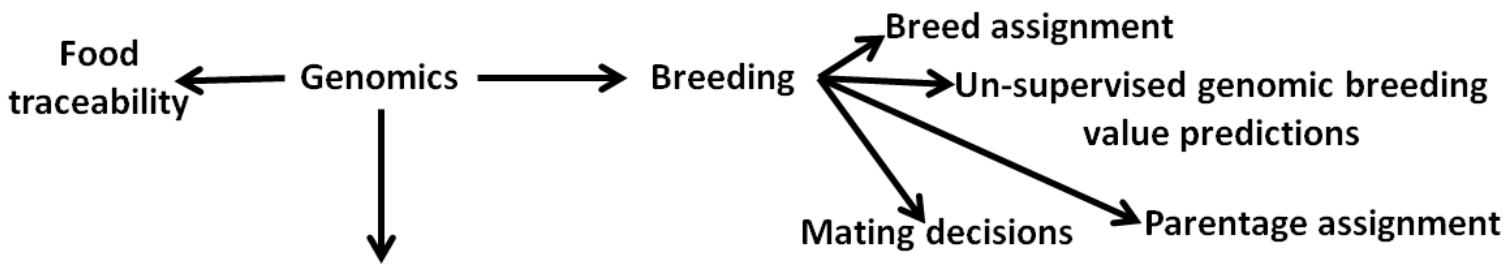
Identify causal

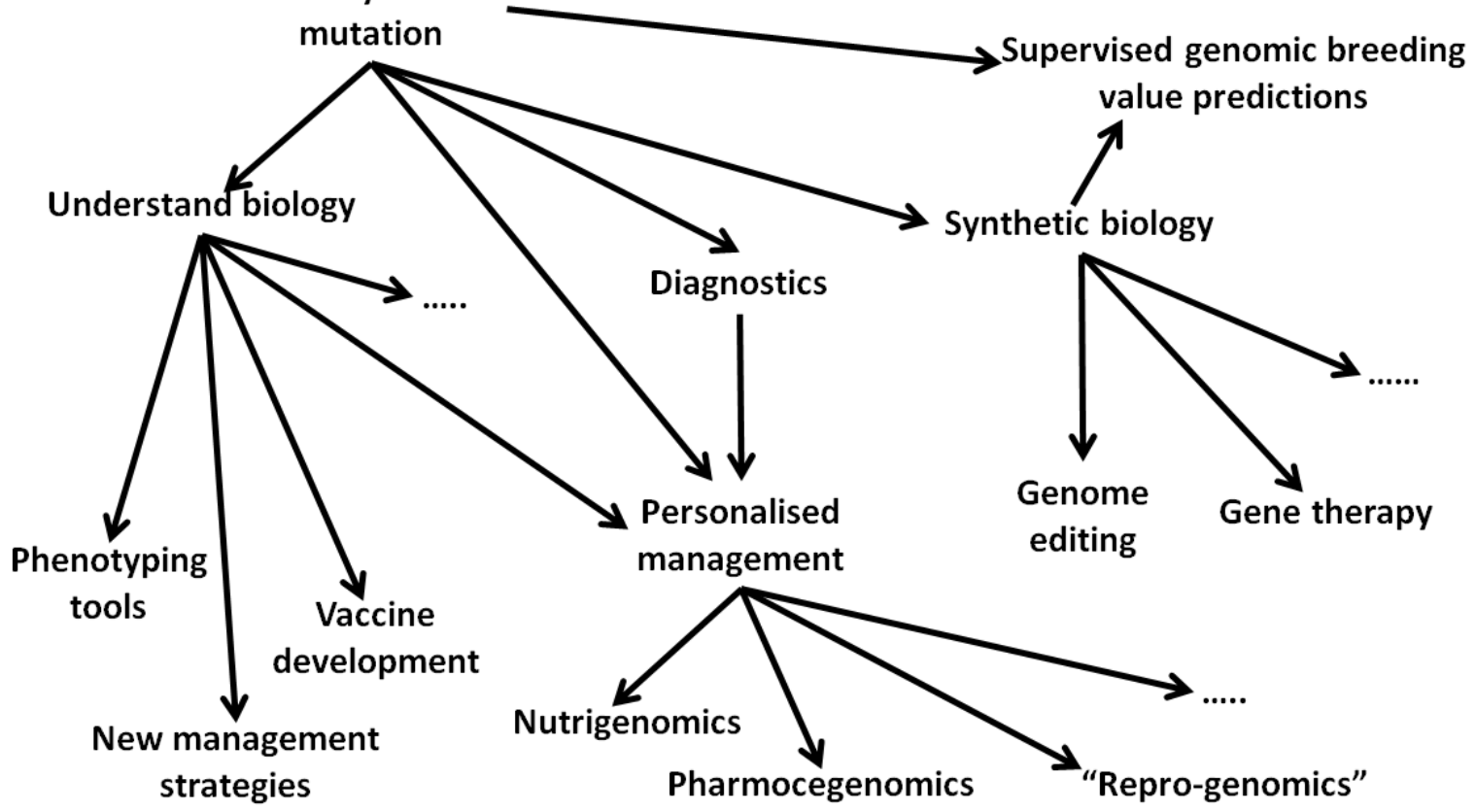




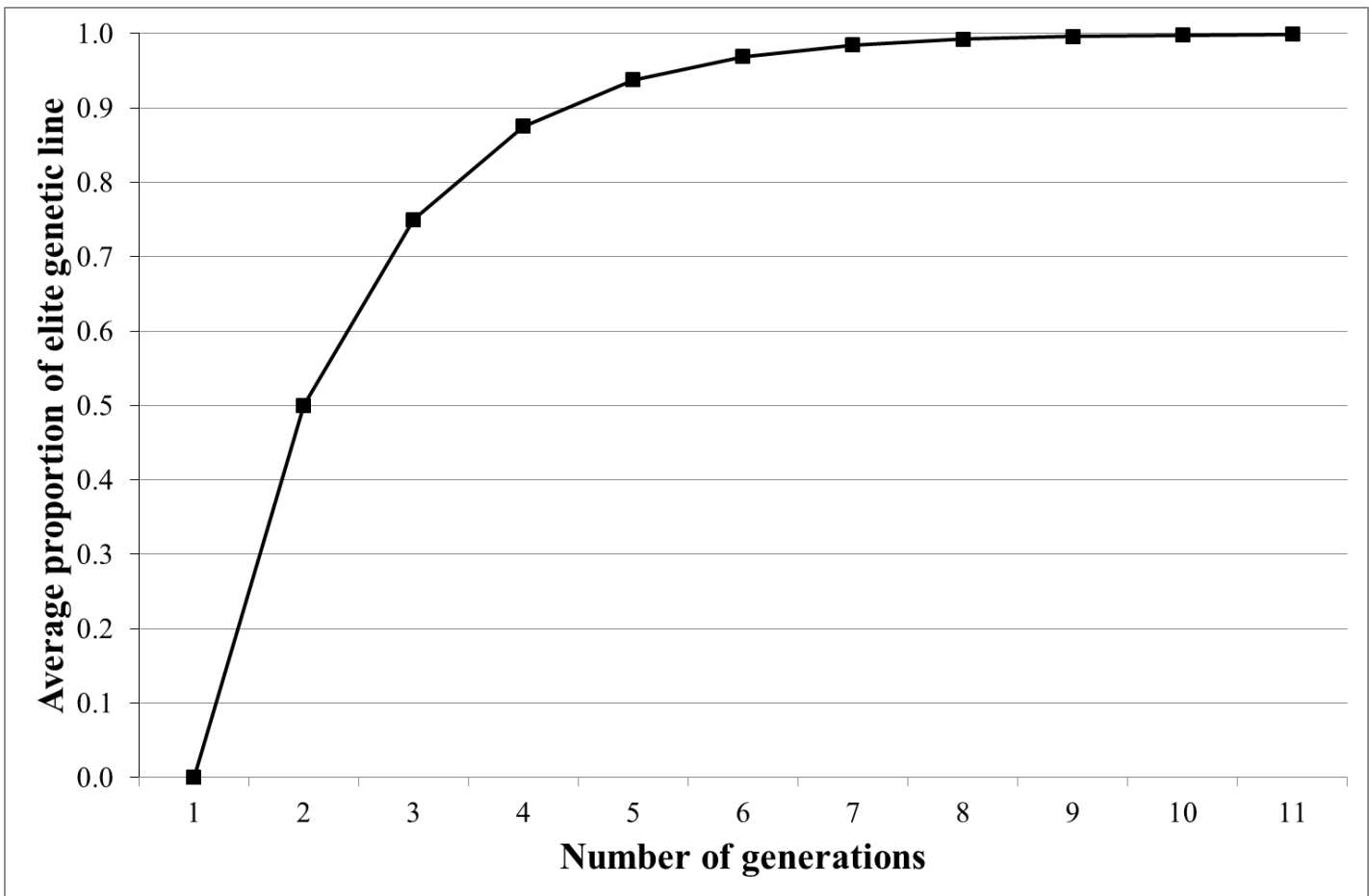

1076 Figure 8. Average proportion of genetically elite line per generation from upgrading of a population.

1077

1078

1079 